\title{
COLLECTING FOR CULTURAL DIVERSITY
}

\section{Margaret Anderson}

On the morning I sat down to begin this paper, Melbourne's daily newspaper, the Age, had chosen to run an interesting combination of stories on its 'Opinion' page. This is a page towards the back of the first news section of the paper, on which writers, thinkers, or general 'opinion makers' express their views on topical issues, or ideas. There was only one main topic this day-Australia's contested black/white history and the Federal Government's inability to come to terms with it.

Under the witty banner headline Our future: let's revise, Australia's Prime Minister, John Howard, was given a blunt warning - John Howard take note: we can achieve a better tomorrow by being honest about yesterday. The second article on the page had a similar message, again summed up in the headline $A$ cruel case of absurd historical denial.' The context for these stories was already well-known to readers of the Age, but I don't expect it to strike an immediate chord elsewhere, so let me explain briefly. For some years now Australia has been embroiled in an intensely political debate over the interpretation of its shared past. Historians, mainly white, began to publish uncomfortable studies of black/white relations, which showed, quite clearly, a process of systematic racial oppression bordering on genocide, extending for most of the period from European arrival in the late eighteenth century. One of the most tragic aspects was the widespread practice of all governments in Australia this century, of systematically removing light-skinned, mixed race children from their indigenous families and placing them in orphanages, or foster homes, to be brought up as 'white'. Some years ago a Royal Commission Inquiry was held on this matter and concluded categorically, that such practices were widespread, that they were based on cruelly racist notions of black inferiority and that the policies, which continued actively into the 1960 s, had many serious contemporary social and cultural ramifications. It called for an officially sponsored program of reconciliation. The report had the popular title Bringing them Home ${ }^{2}$ and its publication caused a furore. The liberal-minded welcomed it as a vital document, providing a framework for the future, but conservatives of all persuasions from the Prime Minister down, found it downright uncomfortable. They dismissed 
22 its findings as exaggerated, as harmful, or as just plain wrong. Aboriginal people were accused of inventing stories of distress, even of suffering from 'false memory syndrome': their stories were compared recently with those of women who have recovered memory of incest or other sexual abuse during childhood under psychotherapy. ${ }^{3}$ Aboriginal elders asked the government for an apology. John Howard expressed his 'regret', but refused to make an apology on behalf of the Australian Government, although every state government has now done so.

At about the same time Australia grappled politically with a new phenomenonthe rise of an intensely conservative, ruralbased, grass roots party, with an antiurban, anti-politician, anti-intellectual, distinctly racist platform. Although not neo-Nazi in the strict sense of the word, it nevertheless drew some inspiration from certain ultra-right American groups, and was particularly opposed to Australia's immigration program. In its first election trial in one state it won a disturbingly significant proportion of the vote, although thankfully it seems now to be on the wane. The name of this party expresses either breathtaking cynicism, or startling naivety - it calls itself One Nation - in clear defiance of Australia's official policy of multiculturalism. In reality what it stands for of course is division, not unity, and it probably has its roots in a very real rural depression and in the dislocation resulting from late-twentieth century globalisation and Thatcherite free-market economics. Small people are hurting and looking for someone to blame.

Although neither of them would thank me for saying this, John Howard and One
Nation have one thing at least in common - they both believe in a mythical golden age, sometime in the recent past - around the $1950 \mathrm{~s}$ and $60 \mathrm{~s}$, when there was full employment, when women knew their place was in the home and stayed there happily bringing up well-mannered, drugfree children; when immigrants were expected to assimilate to the Australian way of life' and be grateful for the new chance they had been given and when the Aborigines were mostly out of sight, out of mind. One of our popular cartoonists drew this image of the Prime Minister and his love affair with the fifties. ${ }^{4}$ Her pointy breasts are the embodiment of male desire, but her dress is decorated with sinister little mushroom clouds, symbolising the British nuclear tests conducted in Central Australia in the early fifties. Many years later it was revealed that numbers of traditional indigenous people had remained undetected in the Maralinga area during the testing, unaware of its dangers. They developed various radiation-related conditions. Incidentally you might like to think about why John Spooner drew his Australia of the fifties without a head - to emphasise its mythical qualities perhaps?

I chose to begin in this round-about way because I wanted to emphasise something which may, in fact, be very obvious to you already. It is the point that the process of making museum collections, especially collections documenting cultural diversity, especially where those collections involve people still living (but not only then), is inherently political - sometimes acutely so. The choices we make, the people whose objects we choose to keep, the stories we record about them, are all potentially political choices. Would 
any thinking person observing this late twentieth century world we live in, seriously argue that history is divorced from politics? I don't think so. We might try and argue that it should be, we might strive in our practice to be as even-handed as we can be, but deep down we know that eventually politics will insinuate itself into the process - maybe in the collecting phase, maybe at the exhibition stage - but eventually.

At the end of the Second World War Australia's leaders were severely shaken. For the first time in our short white history the prospect of invasion had been a real one (the Japanese advance was only finally halted in New Guinea), and to our leaders Australia's wide-open spaces seemed to be beckoning the millions immediately to our north. In an area roughly the size of the United States, Australia's population was then just 7.5 million people. We felt tiny, isolated and vulnerable. The Government decided on a full-scale immigration program, re-settling those of Europe's displaced millions who either wanted to leave their homelands, or had no prospect of returning to them. Over successive 20 year periods Australia's population grew to 11 million and then to around $18 \mathrm{mil}$ lion, resounding to the slogan of the time - 'populate or perish'. Many of these new Australians were either immigrants, or their children. At first the Australian Government thought that it could attract mainly British migrants - so much easier if everyone spoke the same language - but they very quickly recognised that the main interest in immigration was amongst displaced people, many of them Eastern European, and economic immigrants from southern Europe. Gradually the composition of the Australian population became more diverse. Much more gradually official policy caught up with demographic reality. Eventually the Government stopped trying to engineer assimilation and recognised that there could also be cultural strength and security in diversity. Multiculturalism, as official policy, was born. Asian immigration was resisted longer to our abiding shame, but became a significant focus of the immigration program after the end of the Vietnam war. So much so in fact that people of Asian and Middle Eastern origin are now the largest new immigrant groups. To give some indication of the extent of change, estimates of ethnicity in Australia vary considerably, but it is said that anywhere between one quarter and one third of Australians now come from a non-English speaking background, while many more claim that inheritance through their parents or grandparents. At last count there were people from 229 different countries living in Australia."

How did museums respond to this demographic revolution? At first they did not respond at all. At the height of the immigration program in the 1950 s and 60 s, no Australian museum thought to document the process. But then in truth, they were not documenting any other aspect of Australia's history or contemporary society either. In that they were not unusual. Few other museums in the world were doing so either. Australian museums were mostly concerned with natural science and, to a much lesser extent, with anthropology and archaeology. But the anthropologists were all intent on documenting so-called 'traditional' Aboriginal cultural practices and scornfully rejected the non-traditional evidence of cultural adaptation that came their way. It simply 
24 did not occur to them to document the fringe camps most indigenous people then lived in and they had no interest in the experience of people of mixed descent. The first historians came into museums only in the early 1970s. And how did they respond?

A couple of years ago when we were in the middle of planning an exhibition on post-war migration at the Western Australian Museum we came across a concentration camp uniform which had been in the collection since 1972. Apart from the name and address of the donor, and the obvious association with the Nazi camps, there was no information about either the uniform or its owner. Although she had scant hope of finding the donor after twenty years Curator of History Ann Delroy wrote to the address on the donation record seeking information. Incredibly Stefan Gebski, the original donor, replied. $\mathrm{He}$ was still alive, obviously, still at the same address and still prepared to talk about his experiences. Indeed he was bursring to do so. He still smarted from his initial experience with the museum, which in 1972 had accepted his uniform, but had not wanted to hear his story. As far as we have been able to make out, the then curator, who was actually my boss when I first started in museums, thought that to display such an artefact and to tell its associated story, displayed an interest in the macabre which had no place in a museum - or at least not a museum in Australia. He was a lovely man incidentally - clever, thoughtful, one of the few true humanists I have known, but he was blinkered on this. And so the uniform was collected, placed in storage and there it sat, unused and forgotten, for 20 years.
Ann has recently written an account of the process of reconnecting this artefact with its history. ' In the process it became very clear that without Stefan Gebski's help we would have found it impossible to decode the many symbols attached to the uniform, nor, of course, could we have made it meaningful on display through the story of the man who wore it and survived to tell the tale.

Stefan Gebski was born in Poland in 1921. At fifteen he entered the Polish army where he finished his schooling and did his military training. His ambition was to become a lawyer eventually, but that was not to be. When he was eighteen the German army marched into Poland : twelve months later first his father and then Stefan himself were arrested. At first he was imprisoned in his home town, but then in 1941 he was sent to the dreaded Auschwitz Concentration Camp as a political prisoner. Incredibly he managed to escape from Auschwitz during the confusion following a sudden severe thunderstorm and was picked up by the Polish underground. He changed his name and evaded capture for a while, but eventually he was arrested again while trying to escape to Switzerland. For the duration of the war he survived one camp after another, as he was moved from Germany to France.

His uniform displays some of the symbols which, decoded, reveal something of his survival strategies in the camps. $\mathrm{He}$ learned quickly the importance of obtaining inside work for example. The uniforms camp inmates were issued provided little warmth in the freezing winters and inmates were fed too little for them to have much resilience. We discovered later that the fabric of the uniform was woven 
from a sort of wood fibre, which was hard-wearing, but gave little warmth. Wool and cotton were apparently in short supply during the war and were too precious to be wasted on prisoners. In some areas the life expectancy of outside workers was just a few weeks. Gebski learned to make use of his good German to ingratiate himself with camp officials, always seeking little advantages that would increase his chances of survival and always looking to avoid the exhausting outside work. At one stage he was given a clerical job for which he was issued with a pen. He was allowed to sew a pocket onto his jacket so that he could carry the pen. Most prisoners had no pocket: they were expected to have no possessions and so did not need them. He was also allowed to modify his jacket, inserting gussets under the arms to increase freedom of movement. Other symbols identified him as a political prisoner. A red triangle on the top left of the jacket identified him as a political prisoner, a ' $\mathrm{P}$ ' inside the triangle showed that he was Polish. Three red crosses told the camp guards that he was considered a serious political threat and was never to be released. The uniform also showed his number - prisoner no. 138577, because of course such prisoners had no named identities: they were simply numbers.

After the war Stefan moved through various refugee camps. He decided almost immediately that he had no desire to return to Poland and wanted to immigrate. In one of the camps he met and married a young Polish woman, Helena. They had a son, George. In all of this time Stefan kept the concentration camp uniform. At first it was sheer necessity, he simply had no other clothing, but later he and Helena traded the clothing parcels they received from the Red Cross for food and clothing for their son. They were desperate to immigrate and a sickly child meant certain refusal. But it is hard to believe that the choice was as stark as this, especially as Stefan was still wearing the uniform when he arrived in Australia in 1950. The locals laughed at him for wearing pyjamas, but Stefan insists that he still had nothing else. As he says 'We were very poor... We had nothing - no extra clothes only the shoes on our feet and the clothes on our backs.' Later though, and really, I suspect, right from the start, Stefan kept the uniform, as tangible evidence of the horror of the camps. He became obsessed with telling his story, with ensuring that the world would never forget what had happened. It was as if he anticipated the revisionist history of the $1980 \mathrm{~s}$ and $90 \mathrm{~s}$ that attempted to deny the Holocaust.

There is probably no escaping such an experience, but some seem to survive better than others. Stefan survived physically, although he continues to suffer from the long-term effects of starvation, beatings, subjection to freezing conditions and tuberculosis contracted in the camps. But it is his mental state that has caused such distress to his family. He is constantly anxious, suffers periodic depression and has been diagnosed as suffering from clinical paranoia. Unable to escape from his nightmares, he talks about his experiences constantly and has written his memoirs, which he published himself some years ago. He has testified at various war crime trials and continues to believe that Nazi sympathisers threaten both him and his family. This may be partly paranoia, but not completely. He has received death 
26 threats, both personal threats and threats against his family, at different times in Australia and has various notes to prove it. His wife and family, who wish only to move on, refused at first to talk to Ann when she visited, because they can no longer bear his constant reiteration of events.

Now it is clear from this story that Stefan Gebski was able to provide us in the museum with very valuable assistance. Could we in turn do anything for him? Oddly enough, the public recognition which has come from the exhibition of his uniform, with his story, in the context of post-war immigration to Australia seems finally to have brought an approximation of closure to Stefan and his family. Although completely antagonistic at first, Helena eventually relented and attended the exhibition opening with Stefan. So did his son and his grandson. They came as a family very early on the morning the exhibition was to open, partly because Stefan was uncertain about whether he could control his emotions enough for a public ceremony. He was aware that there were to be German representatives present at the function and that he would have to control his anger. We were very glad when he decided to stay. He spent a total of five hours at the exhibition that morning, talking to his family and to others who attended. We had had a number of certificates printed to thank those individuals who had provided special assistance to the exhibition. They were presented by the Arts Minister and one was presented to Stefan. For the very first time ever his history and his perseverance were treated with respect and publicly valued. His grandson was moved to tears by the presentation and said afterwards that he began to understand his grandfather at last. Stefan himself said that it was the most important moment in his new life. I find that perhaps the saddest thing of all. And so maybe, in a very small way, we were able to do something for Stefan and his family also.

I had several points in mind in telling this story. The first and most obvious is the way in which museum approaches to both their collections and the stories attached to them have changed in the intervening two decades. In this case of course, at least the uniform had been accepted into the collection when it was first offered. It might have been rejected as having no relevance at all to Western Australia and its regional history, as I'm sure many other items were at this time. But of what use was it without its story? Very limited use I would suggest. And of course for twenty years or more Stefan Gebski had bitterly regretted giving his uniform to the museum and wished that he could take it back. If he had died in the interim the story would have been lost forever, because almost certainly neither Helena, nor his son, would have been prepared to tell it to us. So much meaning can be lost, so very easily, by museums not listening to what the people who own the objects think is important, rather than what we as collectors assume.

Sometimes the stories people want to tell about their lives through their objects are uncomfortable ones. The history of immigration to Australia was not all sweetness and light. In truth the golden decades of the 1950s and 60s were far more comfortable for white Australians like John Howard than they were for the many European migrant workers who arrived in 
those years, or for just about any indigenous Australian. But even many white Australians found life tough at this time. I have just finished writing the story of my own aunt's struggle to build a house in the 1950s, which makes it clear just how poor many people were at this time and how difficult it was to find housing, with post-war shortages in just about everything. ${ }^{8}$ For immigrants the problem was magnified many times. Many remember those years of first arrival vividly, but it is not always the rosy story of peace and safety, followed by gradual economic stability, that the news reels of the time were so anxious to present. What they remember is certainly the safety and finally having plenty to eat, but they also remember cramped, makeshift accommodation, often in hostels, or army huts, but sometimes also in tents, with little privacy and they also recall the awkwardness of Australians who knew so little about Europe. For immigrant workers assigned to work in rural areas, and many were sent to build roads, railways and other basic infrastructure projects many miles from the main cities, this sort of housing was the norm for years. The difficulty for us in museums is how to collect material to reflect this very common experience, because of course most people disposed of their lumpy old mattresses and awful, prickly, grey army blankets as soon as they could. And while there are some photographs of migrant camps in this period, very few of them are detailed studies of interiors.

When we came to work on our exhibition about post-war immigration to Western Australia it quickly became apparent through oral histories that this was an important experience to document, but noone had thought to do so at the time. And forty years on, the migrant hostels themselves were long since abandoned. The critical breakthrough came through community networks. We appointed a woman who had been a Dutch child migrant after the war to help us with the exhibition. She had kept in touch with many other families from different community groups who had been in the migrant camp with her. And one of those friends, Anna Pankiw, had miraculously kept some of her possessions from that time. Even better she had a photograph of the inside of one of the tents, which showed clearly what the internal arrangements had been. Even in the primitive conditions of tent life along the railway line in isolated, rural Western Australia, Anna Pankiw's mother Helena had carefully arranged some reminders of home - a crucifix, a piece of embroidery - worked on hessian in the first migrant camp - trying in this small way to reconstruct some of the life she had known before. Above all trying to humanise the stark spaces they had to call home. Anna Pankiw was an incredibly generous partner in the process of both collection building and the later display. She had very little to remind her of her mother, who tragically died when she was in her teens, just as the family finally managed to move into their own proper home. One of the few things she had was the piece of embroidery, worked by her mother not long after she arrived in Australia. She also had the crucifix which had hung in the tent, but she immediately gave them all to the Museum and then ran around to find the right sort of material to sew the other coverings she remembered for our reconstruction. It was 
an act of great generosity, and above all of trust, because essentially she was assigning us the tangible memory of her mother. And that is one of the other aspects of collecting evidence of cultural diversity: many of the objects may seem unremarkable in themselves - they are rarely very valuable, sometimes they are not even tasteful - but they have immense emotional significance to the donors.

Sometimes they can also tell surprising stories. Take the piece of embroidery on hessian worked by Anna's mother Helena in that migrant camp for example. Many of the motifs look entirely traditional, Polish patterns remembered from countless pieces worked before the war. Looking at it and knowing nothing of its story, you might think that it was mostly about nostalgia, about ensuring cultural continuities, perhaps about creating a little something of home in an alien land. But in fact it was about far more than this. Because according to Anna, Helena had actually worked the central bird motifs first and they are very far from traditional Polish birds. In fact they are the very colourful West Australian parrots, which were very common in the camp. Helena quite consciously sought inspiration from her new surroundings when she sewed the embroidery, then she filled in the spaces with traditional motifs, blending the old with the new - just what she felt her family was doing in Australia. I have seen other embroidery and lace made by immigrant women which has done the same thing, seeking inspiration in Australia's flora and fauna to create something at once both new and traditional.?

Why did we think it was important to collect this evidence of early poverty?
Partly it was because most of the people we talked to remembered the migrant camps vividly. As their first experience of Australia, the memory of them was strong. And partly because they wanted their children and grandchildren to understand what it had been like for them. As it happened, when the exhibition was presented it also proved to be enlightening to many non-migrant Australians, who simply had no idea what conditions had been like for these early migrants. The news reel pictures of the time were all about happy, laughing families at the beach or having picnics, cheerfully learning English in supportive class rooms, not living in tents for years, not struggling with washing in a kerosene tin out in the hot West Australian sun, or enduring endless teasing from the other kids at the local primary school because their lunch consisted of 'foreign' food. We wondered whether other people might perhaps be offended by this frank exposé of primitive living conditions and early prejudice, but if they were, they did not say so. What they did say in very many messages left in our record book, was that they had enjoyed the exhibition immensely, that they felt humbled by what they had learned and that it was important to present the past accurately. We took great heart from that response. It gave us the courage to attempt a much more radical story in our Aboriginal gallery which opened in early 1999.

Working with community groups in this way, collecting material from such a diverse range of cultures, has meant changing the way we do things in museums. It changes the balance of power, reverses the traditional flow of knowledge. Very often expert knowledge will lie not with the 
curator, but with the community in these projects and the museum must negotiate access to it. Listening becomes a very important skill. A little humility comes in handy too, something curators are not always endowed with!

When I first began in museums in a department of modern history, most of the objects we acquired came to us unsought. They either came via actual donors, who would appear, often a bit apologetically, at the main reception desk, offering to give us things, or they came via auction catalogues. We had a collecting policy which seemed on the surface to be quite comprehensive. It said something along the lines that we would collect material evidence of Western Australian society and technology from 1829 , when the British first arrived, until the present. At that stage I don't remember that it actually identified any areas of particular priority, but I am certain that it did not suggest that we should go out actively to seek evidence of diversity. It was tacitly understood that the material culture of Aboriginal people was the responsibility of the anthropologists, and other groups were never discussed. When someone did suggest that the Museum should begin to document the migration experience of people and aspects of the many different cultural groups already in the State, the two departments argued about who should take on this extra work. When I left Western Australia in 1982 to go to the Migration Museum this squabble was unresolved. And so I was not really very well prepared for the challenges of building the Migration Museum in Adelaide - not that I told the appointment panel that of course!

There were, at that time, no models in other museums to work from and so in a sense, we made it up as we went along. Luckily there was an advisory committee in place, made up of people active in various ethnic community organisations and they provided the first introductions to the communities. They also offered muchneeded advice about political divisions and cultural protocols, both between and within different groups. And armed with that meagre advice I blundered off to talk to groups, seeking their support, seeking advice about what we should attempt to do, and seeking donations. I still remember my first address to a community. Knowing what I now know I probably would have left the official Greek community until later on, but I was very green. I was invited to go and speak to them, so off I went. I was just 30 at this stage incidentally. It was all very formal. They had organised a special meeting to talk about this important project and about how the Greeks might be included and there were several hundred people there I suppose. There was a podium and there were several middle-aged and important looking men who spoke first - in Greek of course. Then they introduced me - in Greek and English and I started. They translated every word I said, so it was a slow process. I thought we would never get to the end of it! Some years later those same Greek men and I laughed about that first meeting, which they freely admitted was designed to show me my place. Almost all of them could speak English perfectly well, but that was not the point. They wanted to tell me, obliquely, that they would help me, but that it would be at least partly on their terms and that respect for their language and heritage was critical. I didn't for- 
get the lesson, although no other community group made quite such a drama of the whole thing I must say.

That issue of respect is a difficult one, because on the one hand respect for differing cultural practices is an essential component in any partnership between a museum and a community. And we are talking about partnerships here, not a one-way process in which the community hands over its objects and the museum takes over from there. There are several issues I want to mention here. One is the old question about authority. Who in the community has the authority to speak and how does this effect first the material collected and then the stories that can be told through it.

At the Migration Museum we had a very close and supportive relationship with the local Polish community. They very early realised the potential of the Migration Museum and were determined that the Poles would be a visible presence in it. They succeeded too, because we needed them as much as they wanted us! But when we first went to talk to them, it was invariably the men who spoke, even where women were also present. Most of their stories were about the war and the objects they wanted to give us reflected that their military uniforms, their medals and so on. Many of them had served with the Free Poles and some of them had, indeed, been very brave men, working with the French Resistance in particular. But on several occasions it turned out that their wives had equally interesting stories to tell about their wartime experiences. They would never have volunteered them, and neither would their husbands incidentally, but sometimes these women's wartime activities had been every bit as brave and dangerous as the men's'. We only found out because we asked them directly, but we were prompted to ask we because within our collecting policy about cultural diversity, we identified gender as a crucial category to consider as well.

Sometimes within the boundaries of respect for a community group's history and culture, problems can still arise. It was a particular issue from time to time at the Migration Museum, especially in our Community Access Gallery, which is a small exhibition space made available to different community groups to present their own exhibitions. Sometimes the view of its past held by one group could be deeply offensive to another. I'm sure you can think of many examples now, but in the early eighties the tensions simmering in the Balkans were less evident - at least to the uninitiated in Australia. We had to be very careful! But it could also arise in the process of making collections, from something as seemingly innocent as the name of the town a particular costume came from for example. In one of our early exhibitions at the Migration Museum we included a rather lovely traditional costume from a particular town in the present province of Macedonia in Greece. The person who donated the costume to us identified herself as Macedonian and so the name of the town given to us was Macedonian. We didn't think to look the place up in an atlas. The Greeks when they saw it were furious and accused us of being pawns of the pan-Macedonian movement. They insisted that the costume be labelled with a Greek name, but there was no way that the Macedonians were going to accept that. They accused us of 
being pawns of Greek imperialism! One side threatened to bomb the Museum, (obliquely - he was a lawyer) the other to picket it! I went home that night, looked at my very small daughter, then only four or five years old, and wondered what sort of job I had landed in. When a rather odd package was delivered to my house a week later, I called the bomb squad. It turned out to be my contact lens sterilising unit which I had left, by mistake, in a hotel interstate, but the parcel was curiously addressed and tensions were so high at the Museum, that I called the police, and they called in the bomb squad, who called in their robot -. and so on. I was very embarrassed to be handed my steriliser, but the police all seemed relaxed about it. I suppose it was a bit of practise for them! The compromise we came to in the end over that costume by the way, was to use both the Greek and the Macedonian name, but it took a very long time, with much to-ing and fro-ing, to reach that compromise. From then on we looked up every place name in an atlas before we recorded the details!

The things communities want museums to collect can sometimes differ from the sorts of things the museum is seeking too. Here is another dilemma. Earlier I suggested the importance of listening to what the people who own things think is important, now I'm suggesting the reverse. Well, perhaps not entirely. The example I have in mind is the widespread tendency of community groups to wish to show themselves in the museum in the best light. If you approach them for material reflecting their community's experience in your country for example, they will almost invariably send you to those who have been most successful. 'Oh, you ably a he) done very well. Made a fortune in business, started as a refugee, the whole migrant success story.' Of course we want material that reflects this sort of story, but we would probably like to balance it with material from someone who didn't do quite so well, or who did downright badly, or even someone who gave up in disgust and went home. Well, you can hardly go and see someone and ask could you please have something to reflect their life of failure can you? And these people rarely volunteer themselves, unlike the successful, who often do! I don't think any museum I know of has found a solution to this particular problem. Most have a great deal of material to record individual success, and some meagre material to reflect general failure. Failure is rarely personalised.

The sort of material museums are offered to reflect cultural diversity also often follows a certain pattern, which does not necessarily reflect the priorities of the collecting policy. Traditional costumes are usually the first items to be volunteered, followed closely by other 'traditional' craft objects, then militaria, then in Australia at least, often the documents recording the immigration process. Many of these objects are very beautiful and mostly museums will accept them gratefully, but they are rarely all that the museum is looking for. Some of what might interest us seems downright silly to a potential donor. 'What do you want that old thing for - I meant to throw it out years ago', they might say, when you enthuse over a bit of improvised, packing-case furniture, or, in Anna Pankiw's case, her old, grey, migrant hostel blankets. At first she 
thought we were crazy. Then she got right into the whole process and started to nag her other friends for similar bits of junk. Of course what I am talking about is museums acquiring collections of broadlybased material culture as evidence of daily life, as well as fine objects of ethnographic significance. Each is equally valid, but they represent different things. To some extent I'm also talking about breaking down cultural stereotypes through the collections we seek. In Australia for example, the 'national costumes' people wear at festivals are mostly dance costumes, worn to keep some tangible link with a past heritage. People don't actually go about wearing national costumes every day. In Australia people who are former immigrants are mostly indistinguishable from everyone else. And I say mostly because some dress codes do still exist - within some groups of Islamic women for example, and in the black mourning costume worn by some eastern and southern European women. Incidentally I don't know of any Australian museum outside the Migration Museum which has tried to collect this sort of clothing. I wonder whether costume museums in Europe have done so?

I referred earlier to the suggestion that museums hoping to document cultural diversity through their collections need to build partnerships with communities. Sometimes these partnerships might exist only to help the museum to build collections in a particular area, but at other times, they might go much further. Indigenous communities in Australia for example, are anxious to be much more involved with all aspects of collection management, from the building of collections, to their handling and display. Many museums now have Aboriginal Advisory Committees to guide them, especially in the management of sensitive materials. As some of you will know, Aboriginal people also have a very particular attitude to skeletal material, which differs from that of most other groups. As a result most Australian museums are now in the process of returning their skeletal remains to communities for re-burial. They also have very strict rules for the appropriate storage of and access to, sacred objects. So-called secret-sacred material tends to carry strong gender taboos for Aboriginal people and by extension for museum workers too. I never went into the secret-sacred store in Western Australia for example, even though I was theoretically responsible for its management. Not surprisingly, almost all of this material in museum collections is male sacred material, since most of it was placed there by male anthropologists and missionaries. Much of this material is being returned also, but not all communities will accept responsibility for it, so museums will still have a long-term role in its management for many years to come I suspect.

Other community groups have also negotiated partnership arrangements with museums which involve the on-going management of collections. The Museum of Victoria agreed with the Victorian Vietnamese community for example, to build collections together and to consult over future directions, but also agreed that the Museum would return the collection to the community if it decided to form its own museum. As far as I know it has not yet done so. But this is a potentially useful approach for museums working with relatively new communities, who would like to preserve aspects of their shared history, 
but worry about losing collections they might need in the future. For the museum of course, it is quite a departure from the norm, since it assumes from the start, the possibility of de-accessioning.

Much of what I have discussed here involves new ways of working for museums. Mostly the experiences in Australia have been very positive, my sad tales of bomb threats notwithstanding. Most of the major museums now have collecting policies which commit them to collecting evidence of cultural diversity, while several have community access exhibition areas in continuous use. And although I have talked mostly about ethnicity and race, I do not mean to define cultural diversity only in this limited sense. Gender is also extremely important and still needs to be championed in museums. Ironically it can be the first casualty in some community exhibitions, especially in communities with very conservative views on women's place. There are other community groups which are beginning to show an interest in museums also. In Western Australia we worked with a group representing people with Down Syndrome for example. We also worked with a support group for women with cancer. Both of these projects resulted in exhibitions which also became virtual exhibitions after they closed in the museum.

Collecting programs like these mean that museums are no longer the exclusive places they were. No longer monocultural, they allow many different people to find aspects of themselves valued and perhaps exhibited. But these collections can sometimes serve a purpose which is even more important than this. I began this paper by talking about the use and misuse of the past - about historical denial and selective amnesia. Perhaps museums which cast their collecting nets widely enough, and which frame their collecting policies thoughtfully enough, can also help to keep the public record honest. Stefan Gebski's concentration camp uniform is one piece of material evidence which continues to affirm the horrors of the Holocaust.

The collections which attest to the oppression of Aboriginal people over the years are equally important, although these are meagre things indeed. The tragedy for Australian museums is that they have 500,000 items of traditional ethnographic material, and only a few hundred items to reflect the realities of living in the white man's world. But amongst those few items is evidence of great significance. Citizenship papers for example, issued to mixed race Aboriginal people, provided that they did not associate with other Aboriginal people. (Other Aboriginal people were denied citizenship in their own country until 1967.) Special passes which allowed specified Aboriginal people to travel through the city to and from work, although others were barred completely. Sad, sad photographs of little Aboriginal girls all dressed in white for Christmas at the orphanage and given presents of white dolls to play with. We haven't been able to find one of those dolls, but we're still looking! Collections like these allow museums to speak with the cultural authority they still hold, however much scholars may question its bases, and to ask their audiences to think honestly both about their shared past and about the future they would wish for. Let me quote to you from one of those articles I mentioned at the beginning. It is an extract from 
34 a radio lecture delivered by a Melbourne historian - Inga Clendinnen. Inga Clendinnen has written extensively on Aztec history, but has also published an historiographical work about the Holocaust and the way it has been treated over time. She said:

As Benedict Anderson makes clear, nations are imaginary communities - and none the less real for that. And nations, especially democratic, ethnically diverse nations like our own, cannot hold together unless they share a common vision as to how the world works, what constitutes the good life, what behaviour is worthy of respect, what behaviour is shameful. So history matters."

I'll add to that - and so museums matter. The collections we make matter, because they are the tangible evidence of past and present lives. And sometimes that tangible evidence is of overwhelming social and political importance.

\section{NOTES}

1. Age, 16 November 1999

2 Human Rights and Equal Opportunity Commission, Bringing Them Home, Report of National Inquiry in to the Separation of Aboriginal and Torres Strait Islander Children and Their Families, Canberra, 1997

3 See the Age articles mentioned in note 1.

4 John Spooner, Age, 16 October 1997. Original in the collection of the Western Australian Museum.

5 There is now a large literature dealing with Australian post-war immigration. G.C. Bolton An Oxford History of Australia, Vol. V, Oxford University Press, 1990 provides a good introduction.

6 Parliament of Australia, Parliamentary Library,
(Geoff Winter) 'Census 96: Countries of Birth of the Australian Population', Research Note 32 1997-98, 23 March 1998, p. 1

7 Ann Delroy, 'Objects and meaning : case-study of a concentration camp uniform', paper presented to the Engendering Archaeology conference, University of New South Wales, July 1999.

8 Margaret Anderson 'Homes, families and respectability : building a house in post-war Australia', paper presented to the Engendering Archaeology conference, University of New South Wales, July 1999.

9 Some years ago at the Migration Museum in Adelaide I did an exhibition on lace and lacemaking which exhibited several such pieces. See Margaret Anderson \& Maieke Knottenbelt, Lace: the Labour and the Luxury Migration Museum, Adelaide, 1986.

10 Age, 16 November 1999. Inga Clendinnen's other publications include Reading the Holocaust, Text Publishing Co., Melbourne, 1998; Ambivalent Conquests : Spaniard and Maya in Yucatan, 1517-1577, Cambridge University Press, 1987 \& The Aztecs : Rise and Fall of an Empire, Cambridge University Press, 1995.

Margaret Anderson är historiker inriktad på nutidshistoria. Hon har som Curator in History arbetat vid Western Australian Museum, Perth, därefter var hon $i$ början av 1980-talet ledare for Migration Museum in South Australia, och lärare i historia och 'material culture studies' vid Monash University i Melbourne. 1994 atervände hon till museet i Perth da som Director of Social and Cultural History. Hon bor numera $i$ Melbourne for att inleda ett arbete med att utveckla vandringsutställningar.

Adr. 17 Mason Street. Hawthorn. Victoria. Aust. 3122.

Fax: 61398186020

email:margaretanderson@bigpond.com 